\title{
A preparative method for Synthesis of 4,5,6-trichloropyrimidine
}

\author{
Stanisław Ostrowski, Jadwiga Swat, and Mieczysław Mąkosza \\ Institute of Organic Chemistry, Polish Academy of Sciences, ul. Kasprzaka 44/52, PL-01-224 \\ Warszawa, Poland; Fax: (+48)-22-6326681 \\ E-mail: stan@icho.edu.pl
}

(received 13 Jul 00; accepted 26 Nov 00; published on the web 04 Dec 00)

\begin{abstract}
The preparative method for synthesis of 4,5,6-trichloropyrimidine (1) from dimethyl chloromalonate and formamidine acetate is reported. In a two-step process the desired compound was obtained in overall yield $64 \%$ for the reaction scale $5-10 \mathrm{~g}$.
\end{abstract}

Keywords: Trichloropyrimidine, dimethyl chloromalonate

\section{Introduction}

Pyrimidine ring is present in a large number of biologically important compounds such as alkaloids, drugs, agrochemicals or antimicrobial agents and, since the early years of this century, numerous studies on the synthesis and structure-activity relationships of pyrimidine derivatives have been reported. ${ }^{1}$ Therefore, preparation of some highly substituted pyrimidins, giving a possibility for further transformations, can be of substantial interest. 4,5,6-Trichloropyrimidine bearing three halogen atoms which can be easily exchanged in $\mathrm{S}_{N} \mathrm{Ar}$ process is expected to be a very useful intermediate for derivatization of this diazine system. Several examples of synthesis of new compounds from 1 have been already reported from our laboratory. ${ }^{2}$

Isomeric to 1, 2,4,6-trichloropyrimidine, is commercially available as it can be easily obtained by the cyclization reaction of urea with alkyl malonates ${ }^{1}$ followed by further treatment of the formed barbituric acid with phosphorus oxychloride. ${ }^{3}$ In a number of papers its biological activity $^{4}$ and transformations into new pyrimidine derivatives ${ }^{5}$ was described. For an ongoing project, we required 4,5,6-trichloropyrimidine and, unexpectedely, we have not found in the literature a convenient, fast, and high-yielded method for prepartion of this compound. 4,5,6Trichloropyrimidine moiety was mentioned in the literature several times and all the important reports are given in reference (6). However, none of the methods described in these papers can be considered as facile preparative synthesis of this compound starting from the simple, inexpensive, and commercially available materials. Usually, they are multi-step transformations which are not selective, ${ }^{6 \mathrm{~b}, 6 \mathrm{c}}$ required specific $^{6 \mathrm{~b}}$ and harsh conditions, ${ }^{6 \mathrm{~b}, 6 \mathrm{~d}, 6 \mathrm{f}}$ or start from the already prepared cyclic derivatives. ${ }^{6 a, 6 e, 6 g}$ In many cases these methods were reported in 
patents. $^{6 \mathrm{~b}, 6 \mathrm{~d}, 6 \mathrm{e}, 6 \mathrm{f}}$

For our two-step synthesis of $\mathbf{1}$ we used dimethyl chloromalonate and formamidine acetate. The first step is the sodium ethoxide promoted cyclocondensation of well-known type, ${ }^{7}$ giving 4,6-dihydroxy-5-chloropyrimidine (4). When 4 without purification was treated with an excess of phosphorus oxychloride at $70-90^{\circ} \mathrm{C}$ in the presence of $N, N$-dimethylaniline, it was converted into the desired 4,5,6-trichloropyrimidine (1) in good overall yield (64\%). It is sufficiently pure for most synthetic purposes. The desired product can be purified by column chromatography using n-hexane / ethyl acetate mixture as eluent.

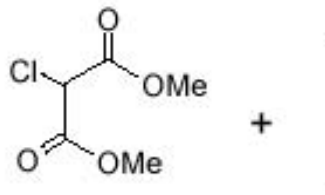

2

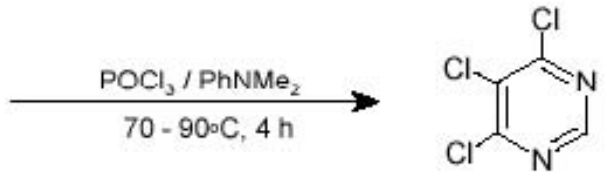

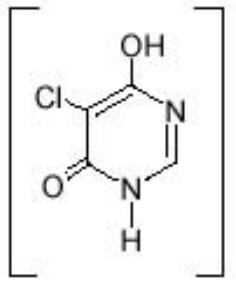

4

This synthesis was optimized for preparation of 5-10 $\mathrm{g}$ of the final product, however it can be probably applied for a larger scale.

\section{Experimental Section}

4,5,6-Trichloropyrimidine. In a three-necked round-bottom flask ( $1 \mathrm{~L})$ equipped with a mechanical stirrer and a thermometer, a solution of sodium ethoxide freshly prepared from sodium $\left(4.15 \mathrm{~g}, 0.18\right.$ mole) in a dry ethanol $(170 \mathrm{~mL})$ is cooled to $0^{\circ} \mathrm{C}$. To the stirred solution, formamidine acetate (Aldrich; $6.14 \mathrm{~g}, 0.059 \mathrm{~mole}$ ) is added gradually. During the addition the temperature is kept between $0^{\circ} \mathrm{C}$ and $2^{\circ} \mathrm{C}$. The mixture is stirred for $c a 0.5 \mathrm{~h}$ and then allowed to warm to $15^{\circ} \mathrm{C}$. The flask is equipped with a dropping funnel, and at this temperature dimethyl chloromalonate (Aldrich; $10.5 \mathrm{~g}, 0.063 \mathrm{~mole}$ ) is added dropwise during a period ca $15 \mathrm{~min}$. The mixture become thick and the temperature is raised slightly to $25^{\circ} \mathrm{C}$. To this thick mixture ethanol $(50 \mathrm{~mL})$ is added and left with stirring for $15 \mathrm{~h}$ at room temperature. Then water $(80 \mathrm{~mL})$ is added and the solution is neutralized with $10 \%$ aqueous $\mathrm{HCl}$ to $\mathrm{pH} \sim 5.5-6.0$. After concentration to $\mathrm{ca} 120 \mathrm{~mL}$, the mixture is extracted with $\mathrm{CH}_{2} \mathrm{Cl}_{2}(2 \times 50 \mathrm{~mL})$ to remove the 
remaining substrates (TLC monitoring; performed on aluminium foil plates pre-coated with silica gel 60F 254, Merck; solvent system: n-hexane / ethyl acetate - 20:1) and the aqueous solution is evaporated to dryness using rotary evaporator $\left(40^{\circ} \mathrm{C}, \mathrm{p} \sim 15\right.$ Torr $)$. The residue is dried in vacuum ( $\mathrm{p} \sim 30$ Torr) over $\mathrm{KOH}$ to give $19.6 \mathrm{~g}$ of colourless solid.

The solid is placed in a three-necked round-bottom flask equipped with a thermometer, a droping funnel, and a reflux condenser, connected at the top with an adsorber with $\mathrm{NaOH}$ solution to neutralize the evolved $\mathrm{HCl}$. $N, N$-Dimethylaniline $(16 \mathrm{~mL}, 15.30 \mathrm{~g}, 0.126 \mathrm{~mole})$ is added and then to the thick mixture, stirred with a magnetic stirrer, $\mathrm{POCl}_{3}(75 \mathrm{~mL}, 123.4 \mathrm{~g}, 0.80$ mole) is slowly added dropwise (ca $1 \mathrm{~h}$ ). When the addition is complete, the reaction mixture is heated to $70^{\circ} \mathrm{C}$ and kept at this temperature for $1 \mathrm{~h}$, and then at $90^{\circ} \mathrm{C}$ for $3 \mathrm{~h}$. After heating it is allowed to cool to room temperature and left with stirring overnight.

The mixture is added dropwise into crushed ice $(1.5 \mathrm{~kg}$ in a $3 \mathrm{~L}$ container) and the solution is stirred for $\mathrm{ca} 3 \mathrm{~h}$ until the temperature is raised to $20^{\circ} \mathrm{C}$. The product was extracted with $\mathrm{Et}_{2} \mathrm{O}(7$ $\mathrm{x} 150 \mathrm{~mL}$ ) and the combined organic layers were washed with saturated solution of $\mathrm{NaHCO}_{3}(3$ x $100 \mathrm{~mL}$ ), dried over $\mathrm{Na}_{2} \mathrm{SO}_{4}$ with $\mathrm{K}_{2} \mathrm{CO}_{3}(5 \%$ wt.), and evaporated to dryness to give $6.9 \mathrm{~g}$ of the crude 4,5,6-trichloropyrimidine (64\%); practically of good grade for most purposes. Column chromatography purification (silica gel 200-300 mesh, Merck AG; eluent: n-hexane / ethyl acetate $-20: 1)$ yielded $5.9 \mathrm{~g}(55 \%)$ of pure product as a white solid.

m.p. 54-56 ${ }^{\circ} \mathrm{C}\left(\mathrm{CHCl}_{3} / \mathrm{n}\right.$-hexane, uncorrected), lit. ${ }^{6 a}$ m.p. $49-51^{\circ} \mathrm{C}$. - ${ }^{1} \mathrm{H}$ NMR (Varian Gemini-

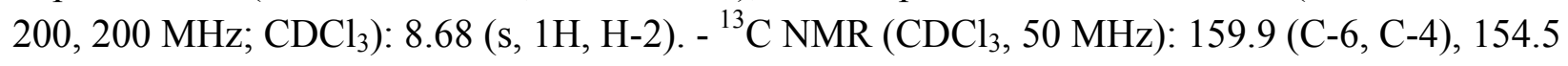
(C-2), 129.1 (C-5). - MS (AMD 604, Intectra GmbH, Germany; electron impact method), $\mathrm{m} / \mathrm{z}$ (given as a \% of relative intensity): 188 (3), $186(30), 184$ (95), 182 (100) [isomeric $\mathrm{M}^{+\bullet}$ ], 151 (8), 149 (48), 147 (76), 124 (3), 122 (21), 120 (32), 98 (1), 96 (9), 94 (14), 88 (10), 87 (13), 86 (30), 85 (35), 59 (3), 51 (7), 50 (6), 49 (4), 47 (10), 38 (5). Anal. Calcd. for $\mathrm{C}_{4} \mathrm{H}_{1} \mathrm{~N}_{2} \mathrm{Cl}_{3}(183.42)$ : C, 26.19; H, 0.55; N, 15.27; Cl, 57.99. Found: C, 25.83; H, 0.71; N, 15.00; Cl, 55.91.

\section{References}

1. Brown, D. J. The Chemistry of Heterocyclic Compounds, The Pyrimidines, Taylor, E. C. Ed., Vol. 52; J. Wiley \& Sons: New York - Chichester - Brisbane - Toronto - Singapore, 1994.

2. Mąkosza, M; Ostrowski, S., Pol. J. Chem. (in print).

3. (a) Beil. VI-23, Reg. No 118284. (b) ref. (1), p. 330.

4. Miyamae, T., Microbiol. and Immunol., 1996, 40, 761.

5. For example: (a) Delia, T. J.; Stark, D.; Glenn, S. K., J. Heterocycl. Chem. 1995, 32, 1177. (b) Delia, T. J.; Nagarajan, A., J. Heterocycl. Chem., 1998, 35, 269. (c) Delia, T. J.; Meltsner, B. R.; Schomaker, J. M., J. Heterocycl. Chem., 1999, 36, 1259. (d) Lee, Y. S.; Kim, Y. H., Synth. Commun., 1999, 29, 1503.

6. (a) Chesterfield, J.; McOmie, J. F. W.; Sayer, E.R., J. Chem. Soc., 1955, 3478. (b) 
Farbenfabriken Bayer A.-G., Ger. Pat. 1,545,313 (Cl. C 07d) (1968); chem, 72: P3497q (1970). (c) Beck, G.; Heitzer, H.; Holtschmidt, H., Angew. Chem., 1974, 86, 134; Angew. Chem., Int. Ed. 1974, 13, 210. (d) Beck, G.; Doering, F.; Holtschmidt, H.; Ley, K. (Bayer A.-G.), Ger. Pat. 2,307,863 (Cl. C 07d) (1974); chem, 81: P152261w (1974). (e) Stauffer Chemical Co., Jpn. Pat. 62,242,631 [87,242,631] (Cl. C07B39/00) (1987); chem, 109: 230508v (1988). (f) Schuendehuette, K.H.; Beck, G.; Findeisen, K.; Henk, H. (Bayer A.-G.), Ger. Pat. DE 3,900,917 (Cl. C07D239/30) (1990); chem, 113: P 172046n (1990). (g) Bay, E.; Timony, P.E.; Leone-Bay, A., J. Org. Chem., 1988, 53, 2858. Ref. (1), pp. 149-239. 